Research Article

\title{
Penanganan kasus abortus inkomplit pada puskesmas PONED di Kabupaten Sumbawa Barat
}

\author{
Success rate in handling incomplete abortion in EmOC primary \\ health care in West Sumbawa
}

Kurniaty ${ }^{1}$, Djaswadi Dasuki², Abdul Wahab ${ }^{3}$

\section{Dikirim:}

17 Mei 2018

Diterima:

25 Januari 2019

\section{Abstract}

Purpose: This study explored the success of incomplete abortion in EmOC PHC in West Sumbawa. Method: This research used descriptive analytic design with mix method approach. Quantitative research with cross sectional design and qualitative research with multiple-case study approach. The quantitative research sample is mother with incomplete abortion and qualitative research sample that is midwife, doctor and head of Puskesmas. Quantitative data analysis used chi-square test and logistic regression. Qualitative data collection using indepth interview method. Results: Handling of successful incomplete abortus was $63,3 \%$ and most of EmOC PHC was complete $67,3 \%$. There is a significant correlation between the success of incomplete abortion handling with the completeness of EmOC PHC. The likelihood of successful completion of incomplete abortion cases in complete EmOC PHC was 4.1 times greater than that of incomplete EmOC PHC. There was a significant relationship between maternal gestational age at abortion with successful incomplete abortion treatment ( $O R=7,1 ; C I 95 \% 1.27-40,2)$. Qualitative results show that EmOC teamwork can influence the success of handling incomplete abortion cases. Conclusion: Completeness of EmOC PHC has relationship with handling of incomplete abortus case. Recommendation: Increased knowledge and competence of health workers in the handling of incomplete abortion, so that in case management is more prepared and competent.

Keywords: EmOC PHC; handling of incomplete abortion; teamwork

\footnotetext{
${ }^{1}$ Mahasiswa Ilmu Kesehatan Masyarakat Universitas Gadjah Mada, kurniabee@gmail.com

${ }^{2}$ Departemen Obstetrik dan Ginekologi FK-KMK Universitas Gadjah Mada

${ }^{3}$ Departemen Biostatistik, Epidemiologi dan Kesehatan Populasi FK-KMK Universitas Gadjah Mada
} 


\section{PENDAHULUAN}

Kematian ibu secara keseluruhan sekitar 99\% terjadi di negara berkembang, 66\% Sub Sahara Afrika, diikuti 21\% Asia (1). Indikator keberhasilan pembangunan kesehatan adalah penurunan dan peningkatan derajat kesehatan, salah satu indikator derajat kesehatan adalah Angka Kematian Ibu (AKI). Survei Demografi Kesehatan Indonesia (SDKI) tahun 2012 menunjukkan peningkatan AKI yang signifikan menjadi 359 per 100.000 kelahiran hidup. Berdasarkan Survei Penduduk Antar Sensus tahun 2015, AKI kembali menunjukan penurunan menjadi 305 kematian ibu per 100.000 kelahiran hidup (2). Penyebab terbesar kematian ibu disebabkan oleh perdarahan $30,2 \%$, hipertensi $27,1 \%$, aborsi $13 \%$ dan infeksi $7,3 \%$ semua kondisi tersebut tidak perlu terjadi jika pelayanan obstetri neonatal esensial dasar (PONED) dapat diakses secara cepat dan tepat (3). Abortus didefinisikan sebagai penghentian kehamilan sebelum janin dapat hidup di luar kandungan, pada usia kehamilan < 20 minggu atau berat janin kurang dari 500 gram (4).

Angka abortus di seluruh dunia adalah sekitar 35 per 1000 wanita yang berusia 15-44 tahun, abortus merupakan salah satu penyebab tingginya angka kematian ibu di Indonesia dari seluruh kehamilan (selain keguguran dan lahir mati), 26\% diantaranya berakhir dengan abortus (5). Sekitar $44 \%$ abortus di dunia adalah ilegal, 64\% abortus legal dan hampir 95\% abortus ilegal terjadi di negara berkembang. sekitar 25\% kematian ibu di Asia yang disebabkan karena abortus masih tinggi. Abortus yang tidak aman bertanggung jawab terhadap 11\% kematian ibu di Indonesia (rata-rata dunia 13\%). Abortus inkomplit memiliki kontribusi dalam kematian ibu, abortus inkomplit merupakan komplikasi 10-20\% kehamilan, penatalaksanaan abortus inkomplit dapat dilakukan secara ekspektatif, medikamentosa dan tindakan bedah dengan kuretase atau aspirasi vakum (6).

Puskesmas memiliki peran sangat penting dalam layanan obstetri. Peningkatan kualitas layanan dan kelengkapan PONED merupakan rangkaian intervensi yang penting dan hemat biaya untuk mengurangi kejadian mortalitas dan morbiditas ibu dan bayi baru lahir (7). Meski demikian, studi tentang efek dari layanan ini kurang mendapat perhatian. Penelitian ini mengeksplorasi efek program PONED terhadap layanan maternal-neonatal terutama berkaitan dengan penanganan abortus inkomplit.

Kabupaten Sumbawa Barat tahun 2017, selama 3 tahun terakhir abortus merupakan kasus terbesar, tercatat jumlah kasus abortus sebanyak 89 yang menyumbang $43 \%$ dari total kasus komplikasi pada ibu hamil bersalin dan nifas yang tersebar pada 9 Puskesmas baik yang PONED maupun Non PONED serta berakhir dengan abortus inkomplit.Aborsi yang tidak aman adalah salah satu penyebab utama kematian ibu terkait kehamilan, hanya sebagian ditangan oleh EmOC dengan menyajikan pendekatan komprehensif (8). Ketersediaan dan pemanfaatan Pelayanan Obstetri Neonatal Esensial Dasar (PONED) merupakan kunci dalam pencapaian Target global dan nasional untuk mengurangi angka kematian ibu dan bayi (9).

Berdasarkan riset fasilitas kesehatan 2011 di Kabupaten Sumbawa Barat, petugas yang mengikuti pelatihan PONED 33,3\%. Dilihat dari kelengkapan alat PONED, ada Puskesmas yang sudah mencapai $80 \%$ dan ada Puskesmas yang capaiannya kurang dari 79\%. Sehingga Puskesmas mampu PONED yang tersedia masih belum maksimal (10). Oleh karena itu peneliti bertujuan ingin mengeksplorasi gambaran keberhasilan Puskesmas PONED dalam penanganan kasus abortus inkomplit, serta bagaimana dukungan dari pemerintah.

\section{METODE}

Penelitian ini menggunakan desain deskriptif analitik dengan pendekatan mix method. Penelitian kuantitatif menggunakan rancangan cross sectional. Penelitian kualitatif dengan metode Multiple case study karena penelitian ini menggunakan jumlah kasus yang banyak untuk memperoleh informasi yang lebih dalam terkait Puskesmas PONED.

Sampel dalam penelitian kualitatif diambil secara purposive sampling sebanyak 6 orang responden yaitu 2 bidan penanggung jawab ruang PONED, 2 dokter, 2 kepala Puskesmas. Penelitian kuantitatif dengan menggunakan teknik total sampling, yakni semua pasien abortus inkomplit pada tahun 2017 sebanyak 52 kasus dengan sebaran; Puskesmas Brang Rea 19 kasus, Puskesmas Seteluk 16 kasus, Puskesmas Jereweh 9 kasus dan Puskesmas Sekongkang 8 kasus.

Analisa data menggunakan uji chi-square untuk melihat hubungan antara masing-masing variabel dan menghitung tingkat kemaknaan $p$-value $<0,05$ pada tingkat kepercayaan 95\%. Analisis multivariabel menggunakan uji logistic regression karena variabel terikatnya berupa data kategorik dengan skala nominal yaitu variabel keberhasilan penanganan abortus inkomplit. Besar hubungan antara variabel bebas dengan variabel terikat apabila variabel luar ikut dipertimbangkan dilihat dari nilai adjusted odds ratio (AOR) tingkat kemaknaan $p$-value $<0,05$ pada tingkat kepercayaan 95\%.

\section{HASIL}

Tabel 1 menunjukkan sebagian besar ibu dalam usia produktif (20-35 thn) sebesar $65,3 \%$ dan ibu yang usia berisiko ( $<20 \&>35$ thn) sebesar $34,6 \%$. Penanganan abortus inkomplit berhasil sebesar $63,3 \%$ dan tidak berhasil sebesar 36,5\%. Kelengkapan Puskesmas PONED sebagian besar telah memiliki fasilitas yang lengkap 
sebesar 67,3\% dan Puskesmas PONED tidak lengkap sebesar 32,6\%. Ibu dengan gravida tidak berisiko (jumlah kehamilan $>4$ kali) lebih banyak sebesar 88,4\% sedangkan gravida berisiko (jumlah kehamilan <4 kali) sebesar $11,5 \%$. Sebagian besar ibu dengan usia kehamilan saat abortus awal sebesar 84,6\% dan abortus telat sebesar $15,3 \%$. Untuk riwayat abortus, ibu yang pernah abortus sebesar 26,9\% dan lebih banyak ibu yang tidak pernah melakukan abortus sebesar 73,0\%.

Tabel 2 menunjukkan bahwa terdapat hubungan yang signifikan antara keberhasilan penanganan abortus inkomplit dengan kelengkapan Puskesmas PONED $(p=0,020)$. Kemungkinan untuk keberhasilan penanganan abortus inkomplit pada Puskesmas PONED yang lengkap lebih besar 4,1 kali dibandingkan dengan Puskesmas PONED yang tidak lengkap. Terdapat hubungan yang signifikan antara keberhasilan penanganan abortus inkomplit dengan usia kehamilan saat abortus ( $p=0,014)$. Kemungkinan untuk keberhasilan penanganan abortus inkomplit pada ibu yang mengalami abortus awal lebih besar 7,1 kali dibandingkan dengan ibu yang mengalami abortus telat. Keberhasilan penanganan abortus inkomplit

Tabel 1. Distribusi penanganan abortus inkomplit dan kelengkapan Puskesmas PONED.

\begin{tabular}{lcc}
\hline \multicolumn{1}{c}{ Variabel } & Jumlah & $\%$ \\
\hline Usia ibu & 34 & 65,3 \\
$20-35$ thn & 18 & 34,6 \\
$\quad<20 \&>35$ thn & & \\
Abortus inkomplit & 33 & 63,4 \\
$\quad$ Berhasil & 19 & 36,5 \\
$\quad$ Tidak berhasil & & \\
Puskesmas PONED & 35 & 67,3 \\
$\quad$ Lengkap & 17 & 32,6 \\
$\quad$ Tidak lengkap & & 11,5 \\
Gravida & 6 & 88,4 \\
$\quad$ Berisiko & 46 & 15,3 \\
$\quad$ Tidak Berisiko & & 84,6 \\
Usia kehamilan saat abortus & 8 & \\
$\quad$ Abortus telat & 44 & 26,9 \\
$\quad$ Abortus awal & & 73,0 \\
Riwayat abortus & 14 & \\
$\quad$ Pernah abortus & 38 & \\
$\quad$ Tidak pernah abortus & & \\
\hline
\end{tabular}

dengan riwayat abortus tidak mempunyai hubungan yang signifikan $(p=0,061)$.

Tabel 3 menunjukkan model adjusted dibangun untuk mengetahui hubungan antara abortus inkomplit dengan kelengkapan Puskesmas PONED. Hasil analisis menunjukan terdapat hubungan yang signifikan $(\mathrm{OR}=4,1 ; 95 \% \mathrm{CI}=1.209$ 14,09) bahwa kemungkinan keberhasilan penanganan abortus inkomplit yang Puskesmas PONED lengkap lebih besar 4,1 kali dibandingkan dengan Puskesmas PONED tidak lengkap. Berdasarkan nilai pseudo $\mathrm{R}^{2}$ pada model ini sebesar 0,07 memberikan makna bahwa kontribusi kelengkapan Puskesmas PONED terhadap keberhasilan pelaksanaan abortus inkomplit 7\%.

Model unadjusted dibangun dengan menyertakan usia kehamilan saat abortus sebagai variabel luar. Pada unadjusted ternyata kemungkinan untuk keberhasilan penanganan abortus inkomplit yang Puskesmas PONED lengkap lebih besar 3,8 kali dibandingkan dengan Puskesmas PONED tidak lengkap.Terdapat hubungan yang signifikan antara variabel keberhasilan penanganan abortus inkomplit dan variabel usia kehamilan saat abortus (OR=6,5; 95\%CI=1,07 - 39,2). Berdasarkan nilai pseudo $\mathrm{R}^{2}$ pada model ini sebesar 0,14 memberikan makna bahwa keberhasilan penanganan abortus inkomplit sebesar $14 \%$ setelah dikontrol dengan variabel usia kehamilan saat abortus.

Analisis multivariabel dibuat dua model untuk melihat adanya perancu (confounding) dalam hubungan antara

Tabel 3. Model adjusted dan unadjusted: Tingkat keberhasilan penanganan abortus inkomplit dengan kelengkapan Puskesmas PONED.

\begin{tabular}{|c|c|c|}
\hline Variabel & $\begin{array}{c}\text { Unadjusted } \\
\text { OR } \\
\text { (CI 95\%) } \\
\end{array}$ & $\begin{array}{c}\text { Adjusted } \\
\text { OR } \\
\text { (CI 95\%) } \\
\end{array}$ \\
\hline PKM PONED & $4.1^{*}$ & $3.8^{*}$ \\
\hline (Lengkap) & {$[1.209,14.09]$} & {$[1.049,13.94]$} \\
\hline Usia Kehamilan Saat Abortus & & $6.5^{*}$ \\
\hline (Abortus awal) & & {$[1.079,39.29]$} \\
\hline $\mathrm{N}$ & 52 & 52 \\
\hline Pseudo $\mathrm{R}^{2}$ & 0.078 & 0.148 \\
\hline AIC & 66.94 & 64.17 \\
\hline
\end{tabular}

Tabel 2. Analisis hubungan kelengkapan Puskesmas PONED dengan keberhasilan penanganan abortus inkomplit.

\begin{tabular}{|c|c|c|c|c|c|c|c|}
\hline \multirow{3}{*}{ Variabel } & \multicolumn{3}{|c|}{ Abortus Inkomplit } & \multirow{3}{*}{$\chi^{2}$} & \multirow{3}{*}{$\mathbf{p}$} & \multirow{3}{*}{ OR } & \multirow{3}{*}{ CI $95 \%$} \\
\hline & Berhasil & Tidak Berhasil & Tetal & & & & \\
\hline & n (\%) & n $(\%)$ & Iotal & & & & \\
\hline \multicolumn{8}{|l|}{ Puskesmas PONED } \\
\hline Lengkap & $26(74,2)$ & $9(25,7)$ & 35 & 5,4 & 0,020 & 4,12 & $1,20-14,0$ \\
\hline Tidak Lengkap & $7(41,1)$ & $10(58,8)$ & 17 & & & 1 & \\
\hline \multicolumn{8}{|c|}{ Usia Kehamilan Saat Abortus } \\
\hline Abortus Awal & $31(70,4)$ & $13(29,5)$ & 44 & 6,0 & 0,014 & 7,15 & $1,27-40.2$ \\
\hline Abortus Telat & $2(25,0)$ & $6(75,0)$ & 8 & & & 1 & \\
\hline \multicolumn{8}{|l|}{ Riwayat Abortus } \\
\hline Pernah abortus & $6(42,8)$ & $8(75,1)$ & 14 & 3,5 & 0,061 & 3,2 & $0,91-11,6$ \\
\hline Tidak Pernah abortus & $27(71,0)$ & $11(27,5)$ & 38 & & & 1 & \\
\hline
\end{tabular}


variabel bebas dan variabel terikat. Dalam penelitian ini tidak didapatkan confounding karena nilai OR tidak mengalami perubahan dan nilai $p$-value tetap signifikan.

\section{BAHASAN}

Penelitian ini menganalisis hubungan antara kelengkapan Puskesmas PONED dengan keberhasilan penanganan abortus inkomplit serta variabel luar (riwayat abortus, usia kehamilan saat abortus) yang mempunyai hubungan dengan keberhasilan penanganan abortus inkomplit. Puskesmas PONED merupakan pusat pelayanan kesehatan dasar primer, mempunyai kewenangan dalam penanganan abortus, diantaranya abortus inkomplit dengan kewenangan melakukan kuretase (11).

Penelitian ini menunjukkan terdapat hubungan antara kelengkapan Puskesmas PONED dengan keberhasilan penanganan abortus inkomplit. Hal ini sesuai dengan hasil penelitian yang dilakukan oleh Ariani (12), bahwa keberhasilan penanganan kasus abortus inkomplit dapat dipengaruhi oleh kelengkapan Puskesmas PONED $(p=0,05)$. Kelengkapan Puskesmas PONED mencakup tenaga, alat, ruangan, obat-obatan. Begitu juga penelitian oleh Mujiati (13) menyatakan bahwa Puskesmas mampu PONED merupakan bagian dari jaringan pelayanan obstetrik dan neonatal di Kabupaten/Kota sangat spesifik daerah, namun ada beberapa kriteria pengembangan untuk menjamin kualitas, diantaranya ketersediaan, kelengkapan dan kecukupan alat kesehatan dan obat PONED. Alat dan obat PONED menjadi salah satu syarat yang harus dipenuhi oleh Puskesmas PONED. Jenis alkes PONED sebanyak 26 jenis dan obat PONED sebanyak 17 jenis. Ketersediaan dan kecukupan alat dan obat PONED di Puskesmas PONED di 5 regional di Indonesia masih rendah. Hal tersebut dapat dilihat dari angka rata-rata yang masih berada di bawah $20 \%$. Rendahnya ketersediaan dan kecukupan alat dan obat PONED tersebut dapat menyebabkan tidak optimalnya pelayanan/penanganan yang seharusnya dapat dilakukan jika alat dan obat PONED tersedia dan lengkap.

Hasil penelitian menunjukkan bahwa tidak adanya hubungan yang signifikan antara riwayat abortus dengan keberhasilan penanganan abortus inkomplit. Hal ini sejalan dengan penelitian Iqbal (14) yang menyatakan bahwa riwayat abortus sebelumnya tidak mempengaruhi keberhasilan tindakan penanganan abortus inkomplit. Begitupun dengan penelitian yang dilakukan oleh Behroozik (15) menyatakan bahwa riwayat abortus tidak berhubungan dengan keberhasilan penanganan abortus $(p=0,371)$. Riwayat abortus pada penderita abortus merupakan predisposisi terjadinya abortus berulang, setelah sekali mengalami abortus penderita mempunyai risiko $15 \%$ abortus berulang.
Abortus merupakan penghentian kehamilan sebelum janin dapat hidup di luar kandungan, pada usia kehamilan $<20$ minggu atau berat janin kurang dari 500 gram (4). Usia abortus dapat diklasifikasi menjadi 2: abortus awal dengan usia kehamilan kurang dari 3 bulan (12 minggu) dan abortus telat dengan usia kehamilan lebih dari 3 bulan (12 minggu sampai 20 minggu), dimana ibu yang aborsi pada trimester kedua (usia kehamilan $\geq 12$ minggu) berisiko lebih tinggi, lebih mahal dan lebih sulit diakses daripada aborsi pada kehamilan lebih awal (16).

Penelitian ini menunjukkan ada hubungan antara usia kehamilan saat abortus dengan keberhasilan penanganan abortus inkomplit. Hal ini sejalan dengan penelitian Janiak (16) yang mengatakan dimana ibu yang aborsi pada trimester kedua (usia kehamilan $\geq 12$ minggu) berisiko lebih tinggi, lebih mahal dan lebih sulit diakses daripada aborsi pada kehamilan lebih awal, keberhasilan penanganan abortus inkomplit lebih berhasil pada usia kehamilan awal dibandingkan pada usia kehamilan lebih dari 12 minggu dengan nilai $(p=0.03)$. Penelitian yang dilakukan oleh Behroozik (15) menunjukkan bahwa abortus dengan usia lebih dari 10 minggu kemungkinan gagal lebih besar dibandingkan dengan usia kehamilan di bawah 10 minggu ( $p=0.002$ ). Usia kehamilan saat abortus berpengaruh terhadap keberhasilan penanganan abortus inkomplit. Dilihat dari usia kehamilan awal pertumbuhan janin dengan ukuran 32-43 mm dan berat sekitar 7 gram serta belum terbentuknya placenta maka untuk evakuasi sisa jaringan lebih mudah, dengan menggunakan prosedur medis dan menghindari prosedur invasive, menghindari anestesi. Teknik medical dengan pemberian misoprostol $200 \mathrm{mg}$ hingga $600 \mathrm{mg}$ sehingga untuk kebutuhan kuretase lebih jarang dibutuhkan dengan usia kehamilan awal, sedangkan untuk usia abortus telat pertumbuhan janin sudah lebih besar sekitar $63 \mathrm{~mm}$ dengan berat 19 gram sehingga penanganan sampai dengan tingkat bedah, kuret untuk membersihkan sisa jaringan (17).

Pelatihan kepada tim PONED dapat meningkatkan kompetensi, monitoring dan evaluasi untuk menjaga kualitas mutu pelayanan tenaga kesehatan dalam keberhasilan penanganan kasus abortus, saat ini belum ada consensus umum tentang apakah ada alat penilaian khusus lebih baik disesuaikan untuk mengevaluasi kerja tim dalam keadaan darurat obstetrik (1).

Hasil penelitian menunjukkan bahwa kerjasama dalam tim PONED mempengaruhi dalam proses penanganan kasus abortus inkomplit, dalam hal ini komunikasi bidan dan dokter saling memberikan informasi terkait pasien yang mengalami abortus dan perlu penanganan yang adekuat. Hasil penelitian yang dilakukan oleh Onwochei (18) menyatakan pelatihan dan simulasi berbasis tim dapat meningkatkan keselamatan pasien, dalam penanganan kasus dengan meningkatkan komunikasi, pengambilan keputusan, dan kinerja anggota tim. 


\section{SIMPULAN}

Puskesmas PONED lengkap memiliki 4 kali lebih besar dapat berhasil dalam menangani abortus inkomplit dibanding Puskesmas PONED yang tidak lengkap. Usia kehamilan saat abortus memiliki hubungan dengan keberhasilan penanganan abortus inkomplit, sedangkan riwayat abortus tidak terdapat hubungan dengan keberhasilan penanganan abortus.

Bagi petugas kesehatan perlu peningkatan pengetahuan serta kompetensi tenaga kesehatan dalam penanganan abortus inkomplit, sehingga dalam penatalaksanaan kasus lebih siap dan kompeten. Bagi Dinas Kesehatan agar meningkatkan kompetensi tenaga kesehatan yang belum terlatih PONED, mengatur distribusi tenaga kesehatan yang terlatih PONED pada Puskesmas PONED yang sesuai dengan kebutuhan, melengkapi fasilitas dan melengkapi peralatan Puskesmas PONED teruma penyediaan AVM dalam mempermudah penanganan kasus abortus inkomplit.

\begin{abstract}
Abstrak
Tujuan: Untuk mengetahui tingkat keberhasilan penanganan kasus Abortus Inkomplit pada Puskesmas PONED di Kabupaten Sumbawa Barat. Metode: Penelitian ini menggunakan desain deskriptif analitik dengan pendekatan mix method. Penelitian kuantitatif dengan rancangan cross sectional dan Penelitian kualitatif dengan pendekatan studi kasus jamak. Sampel penelitian kuantitatif adalah ibu dengan abortus inkomplit dan sampel penelitian kualitatif yaitu bidan, dokter dan kepala Puskesmas. Analisis data kuantitatif menggunakan uji chi-square dan regresi logistik. Pengumpulan data kualitatif dengan metode indepth interview. Hasil: Penanganan abortus inkomplit yang berhasil sebesar 63,3\% dan sebagian besar Puskesmas PONED sudah lengkap sebesar 67,3\%. Terdapat hubungan yang signifikan antara keberhasilan penanganan abortus inkomplit dengan kelengkapan Puskesmas PONED. Kemungkinan untuk keberhasilan penanganan kasus abortus inkomplit pada Puskesmas PONED lengkap 4,1 kali lebih besar dibandingkan dengan Puskesmas PONED tidak lengkap. Terdapat hubungan yang signifikan antara usia kehamilan ibu saat abortus dengan keberhasilan penanganan abortus inkomplit [OR=7,1 (CI95\%:1,27-40,2)]. Hasil studi kualitatif menunjukkan kerja sama tim PONED dapat mempengaruhi keberhasilan penanganan kasus abortus inkomplit. Simpulan: Kelengkapan Puskesmas PONED memiliki hubungan dengan keberhasilan penanganan kasus abortus inkomplit.
\end{abstract}

Kata Kunci: Puskesmas PONED; penanganan abortus inkomplit ; kerjasama tim 


\section{PUSTAKA}

1. Policy guidance for health systems: 2nd edition. Geneva: Reproductive Health Matters. 2012;20(39):2057.

2. Kementerian Kesehatan Republik Indonesia. Profil Kesehatan Indonesia Tahun 2015. Jakarta: Kementerian Kesehatan Republik Indonesia, 2016.

3. Myers BA, Fisher RP, Nelson N, Belton S. Defining remoteness from health care: integrated research on accessing emergency maternal care in Indonesia. AIMS Public Heal. 2015;2(3):256-73.

4. Cunningham F, Leveno K, Bloom S, Spong CY, Dashe J. Williams Obstetrics, 24e. Texas: Mcgraw-hill; 2014.

5. Kuntari T, Wilopo SA, Emilia O. Determinan Abortus di Indonesia. National Public Health Journal. 2010;4(5):223-9.

6. Blum J, Winikoff B, Gemzell-Danielsson K, Ho P, Schiavon R, Weeks A. Treatment of incomplete abortion and miscarriage with misoprostol. International Journal of Gynecology \& Obstetrics. 2007;99(S2).

7. Abegunde D, Kabo IA, Sambisa W, Akomolafe T, Orobaton N, Abdulkarim M, et al. Availability, utilization, and quality of emergency obstetric care services in Bauchi State, Nigeria. International Journal of Gynecology \& Obstetrics. 2015;128(3):251-5.

8. Healy J, Otsea K, Benson J. Counting abortions so that abortion counts: Indicators for monitoring the availability and use of abortion care services. International Journal of Gynecology \& Obstetrics. 2006;95(2):209-20.

9. Muganyizi P, Maswanya P, Kilima S, Stanley G, Makuwani A, Massaga J, et al. Availability, Coverage and Geographical Distribution of Emergency Obstetric and Neonatal Care Services in Tanzania Mainland. J Gynecol Obstet. 2017;5(1):1-8.

10. Badan Penelitian dan Pengembangan Kesehatan. Laporan Rifaskes 2011. Jakarta: Kementerian Kesehatan RI, 2012.

11. Paxton A, Bailey P, Lobis S, Fry D. Global patterns in availability of emergency obstetric care. International Journal of Gynecology \& Obstetrics. 2006;93(3):300-7.

12. Ariani Shinta. Kejadian dan keberhasilan penanganan kasus perdarahan pada puskesmas pelayanan obstetri neonatal emergensi dasar (PONED) di Kabupaten Agam Sumatera Barat: Universitas Gadjah Mada; 2008.

13. Mujiati M, Lestary H, Laelasari E. Kesiapan Puskesmas PONED (Pelayanan Obstetri Neonatal Emergensi Dasar ) Di Lima Regional Indonesia Media Penelitian dan Pengembangan Kesehatan. 2014;24(1):36-41.

14. Iqbal MJ, Risanto S. Perbandingan Antara Misoprostol dan Kuretase dalam Penatalaksanaan Abortus Inkomplet. Yogyakarta: Universitas Gadjah Mada; 2013.

15. Behroozi-Lak T, Derakhshan-Aydenloo S, Broomand F. Evaluation of effect of letrozole prior to misoprostol in comparison with misoprostol alone in success rate of induced abortion. Journal of gynecology obstetrics and human reproduction. 2017.

16. Janiak E, Kawachi I, Goldberg A, Gottlieb B. Abortion barriers and perceptions of gestational age among women seeking abortion care in the latter half of the second trimester. Contraception. 2014;89(4):322-7.

17. Obstetricians ACo, Gynecologists. Medical management of first-trimester abortion. ACOG practice bulletin no. 143. Obstet Gynecol. 2014;123:676-92.

18. Onwochei DN, Halpern S, Balki M. Teamwork assessment tools in obstetric emergencies: a systematic review. Simulation in Healthcare. 2017;12(3):165-76. 